\title{
SISTEMA DE INFORMAÇÃO GERENCIAL APLICADO AO AGRONEGÓCIO DA UVA NA REGIÃO DO POLO BRASILEIRO DE FRUTAS
}

\author{
Suelena Ferreira Oliveira* \\ Almir Silveira Menelau**
}

RESUMO: O estudo foi realizado na região São Francisco-PE, no âmbito do agronegócio da uva. A pesquisa teve como objetivo responder os seguintes questionamentos: como está estruturado o Sistema de Informação Gerencial (SIG) no âmbito do agronegócio da uva na região do São Francisco/PE, considerando os atores Produtores Rurais e Embrapa? E quais são os efeitos SIG sobre o desempenho das unidades produtivas pesquisadas? Como proposta metodológica buscou-se a configuração do SIG pela perspectiva Insumo-Transformação-Produto. Para tanto foram aplicados questionários aos produtores rurais e à Embrapa. No que se refere aos resultados foi identificada divergência de percepção entre a instituição pesquisada e os produtores rurais. Concluiu-se que atualmente os produtores rurais tratam a informação como insumo tão importante quanto qualquer outro recurso de entrada do sistema. Neste contexto, a parceria com a Embrapa e o fluxo de informações entre estes atores da cadeia produtiva impactaram positivamente no resultado final do agronegócio da uva na região pesquisada.

PALAVRAS-CHAVE: Sistema de informação gerencial. Perspectiva insumotransformação-produto. Agronegócio. Uva.

\section{MANAGEMENT INFORMATION SYSTEM APPLIED TO GRAPEVINE AGRIBUSINESS WITHIN THE BRAZILIAN FRUIT REGION}

ABSTRACT: Current study on grapevine agribusiness was undertaken in the São Francisco region, in the state of Pernambuco, Brazil. The following issues were raised: How is the Management Information System (MIS) structured within agribusiness in the São Francisco region when the rural producers and Embrapa agents are taken into account? Which are the MIS effects on the performance of production units

\footnotetext{
Mestre pela Universidade Federal Rural de Pernambuco, do Programa de Pós-graduação em Administração e desenvolvimento rural (PADR), Brasil. Docente da Faculdade Paraíso do Ceará, Brasil.

E-mail: suoliveira09@gmail.com

** Docente Doutor do Programa de Pós-graduação em Administração e Desenvolvimento Rural (PADR), da Universidade Federal Rural de Pernambuco (UFRPE), Brasil.
} 
under analysis? MIS is methodologically seen from the input-transformation-product perspective. Questionnaires were sent to rural producers and to the Embrapa. Results reveal divergence in perspective between the institution and farmers. Results show that rural producers deal with information on input as any other resource for entrance into the system. Joint venture with Embrapa and information flow among the agents of the production chain has positively impacted the final result of vine agribusiness in the region analyzed.

KEY WORDS: Management information system; Input-transformation-product perspective; Agribusiness; Grapevines.

\section{INTRODUÇÃO}

A complexidade típica das organizações do século XXI exige decisões assertivas que potencializem a competitividade. Novas formas de gestão têm foco nos bens intangíveis e substituem os moldes taylorianos que estavam centrados nos bens tangíveis (ANGELONI, 2003). Neste contexto, a informação é o elemento fundamental para a tomada de decisão e serve como insumo para as organizações atuais.

O período da Revolução Industrial, ocorrida entre os séculos XVIII e XIX, reflete um momento de grandes mudanças para as organizações. A produção individual foi substituída pela produção mecanizada em larga escala. Naquele momento, as decisões estavam intrinsecamente relacionadas a aspectos como aumento de produtividade e, consequentemente, reduções de custos. O grande desafio direcionava-se à eficiência.

Embora as intensas mudanças ocorridas em decorrência da Revolução Industrial tenham resultado em grande impacto para as organizações da época, o ambiente era estável e sem grandes incertezas. Havia demanda para a produção em larga escala, os consumidores estavam ávidos para consumir e eram pouco exigentes pela própria conjuntura do período. A complexidade estava mais atrelada a aspectos operacionais internos do que a ameaças ambientais.

No final do século XX e início do XXI, a mudança passou a ser compreendido como sinônimo de dinamismo e complexidade frente às dinâmicas 
organizacionais. Deste modo, "vivencia-se uma nova ordem que tem suas bases nas mudanças paradigmáticas por que passa esse fim de século, tanto do ponto de vista social, econômico, cultural, político, tecnológico e outros" (BORGES, 2000, p. 25). E, sendo assim, a sociedade mudou, as exigências mudaram e o ambiente tornou-se dinâmico impulsionando uma complexidade nas organizações não percebidas em épocas anteriores.

Quanto ao agronegócio, este envolve atividades essencialmente competitivas. As transformações na agricultura induziram as empresas rurais a buscarem processos de gestão de forma profissional e especializada. Neste sentido, Nunes $^{3}$ (2015) afirma que cabe ao moderno produtor rural aplicar os recursos disponíveis com eficiência para garantir que sua atividade tenha sucesso. Para tanto, ainda conforme o autor (2015, p. 1) a "obtenção de informações sobre os fatores que interagem na lavoura e de como se podem maximizar os seus efeitos parece crucial".

De acordo com a Embrapa (2015) $)^{4}$, os maiores produtores de uva do Brasil estão situados na região de Petrolina-Juazeiro, no denominado polo Agroindustrial. Conforme dados do IBGE (2013), Petrolina encontra-se em primeira colocação no que se refere à produção de frutas no Brasil com valor de produção frutícola de R\$918 milhões, valor este que corresponde a 3,9\% do total nacional. O aumento ocorrido foi de 48,6\% (IBGE, 2013), quando comparado ao ano de 2012, cuja produção foi de $\mathbf{R} \$ 617.766$ mil (IBGE, 2012). A impulsão no crescimento se deu em função da produção de uva que correspondeu a 48,1\% do valor total da produção de frutas no município de Petrolina (IBGE, 2013).

Alguns dos produtores da uva já alcançaram o mercado externo. Entre 1991/1995, a área plantada com uva de mesa cresceu em 71,8\%. A área foi expandida de 2.620 hectares para aproximadamente 4.500 hectares com aumento de produção de 344\% aproximadamente. Foram gerados cerca de 18.000 empregos diretos (EMBRAPA, 2015).

3 Disponível em: $<$ http://www.senar.org.br/agricultura-precisao/artigos-e-palestras/artigo-a-agricultura-de -precisao-como-ferramenta-para-o-produtor-rural/>. Acesso em: 20 jan. 2015.

4 Disponível em: < http://www.cnpma.embrapa.br/projetos/prod_int/regiaosf.html>. Acesso em: 26 maio 2015. 
Para Silva e Coelho $(2010)^{5}$, as novas exigências fomentam a necessidade de um modelo de gestão profissional dos viticultores que, conforme os autores, além de cumprirem o seu papel de abastecer o mercado doméstico devem ser capazes de competirem no mercado externo. Neste sentido, destacam que em resposta à evolução da sofisticação do mencionado mercado os atores que compõem o agronegócio da uva buscam oferecer produtos que atendam a qualidade exigida pelos diversos mercados.

O presente estudo foi realizado na região do submédio São Francisco-PE, mais especificamente no município de Petrolina/PE, no âmbito do agronegócio da uva, em função de sua importância socioeconômica para a região mencionada e para o Estado de Pernambuco.

Deste modo, este estudo teve como objetivo responder aos seguintes questionamentos: como está estruturado o Sistema de Informação Gerencial no âmbito do agronegócio da uva na região do São Francisco/PE, dados obtidos pelos Produtores rurais e Embrapa? E quais são os efeitos SIG sobre o desempenho das unidades produtivas pesquisadas?

Segundo a Embrapa (2001) $)^{6}$, no polo brasileiro de frutas, o denominado Polo Agroindustrial de Petrolina-Juazeiro, encontram-se os maiores e mais lucrativos produtores de manga e uva do país; uma região onde a internacionalização foi alcançada por alguns empresários antes mesmo dos mercados internos (EMBRAPA MEIO AMBIENTE, 2001). Bustamante $(2009)^{7}$ destaca que, com resultados expressivos, o polo fruticultor (em especial o da região abrangida pelos municípios nordestinos de por Juazeiro, na Bahia, e Petrolina, em Pernambuco) tem despontado em nível nacional tendo em vista que são marcadas por fatores como a elevada especialização da mão-de-obra e inovações tecnológicas.

Percebe-se que as empresas rurais inseridas no contexto do agronegócio não atuam de forma isolada, uma vez que estão inseridas em um ambiente dinâmico e complexo interagindo com uma série de forças. Essas empresas necessitam tomar

5 Disponível em: <http://www.cpatsa.embrapa.br:8080/sistema_producao/spuva/Caracterizaca_social_ da_\%20videira.html >. Acesso em 26 maio 2015.

6 Disponível em: $<$ http://www.cnpma.embrapa.br/projetos/prod int/regiaosf.html $>$. Acesso em: 26 maio 2015.

7 Disponível em: <http://www.bnb.gov.br/projwebren/Exec/artigoRenPDF.aspx?cd_artigo_ren=1120> Acesso em: 26 maio 2015. 
decisões considerando os agentes que interagem com ela e com os quais mantêm interdependência neste ambiente, destarte, operam em um contexto sistêmico.

Neste sentido, as organizações rurais são tidas como sistemas abertos que interagem com seu ambiente e precisam, entre outras coisas, de informações contidas no mesmo para tomarem decisões e retroagirem ao ambiente. As informações são fundamentais para redução da incerteza e para lidar com a complexidade.

\subsection{SISTEMAS}

No tocante aos Sistemas, o termo na definição de Bertalanffy (2012) abrange uma série de campos dos quais as empresas industriais fazem parte. Conforme próprio autor, o surgimento de máquinas autocontroladas das mais simples às complexas resultou no pensamento em termos de "sistemas". Maxiamiano (2007, p. 308) por sua vez destaca que sistema pode ser conceituado como "[...] um todo complexo organizado; é um conjunto de partes ou elementos que formam um todo unitário ou complexo. Um conjunto de partes que interagem e funcionam como todo é um sistema".

O enfoque sistêmico atua como resposta a tal complexidade. Bertalanffy (2012) cita que a realização de certo objetivo, de modo eficiente, em complexas redes de interações requer um especialista ou uma equipe de especialistas de sistemas capaz de realizarem as melhores escolhas que resultem em eficácia. $\mathrm{O}$ autor destaca que

isto exige técnicas complicadas e computadores para resolverem problemas que transcendem de muito a capacidade de qualquer matemático individual tanto os equipamentos (hardware) dos computadores, da automação e da cibernética quanto os "programas" (software) da ciência dos sistemas representam uma nova tecnologia. Tem sido chamada a Segunda Revolução Industrial, que se vem desenvolvendo apenas há poucos decênios (BERTALANFFY, 2012, p. 22).

A partir da Teoria de Sistemas é possível entender as organizações como subsistemas capazes de gerar produtos ou serviços resultantes de processo e informação. A ideia de eficiência e de eficácia foi revista considerando, a partir de então, o contexto externo da organização (NOGUEIRA, 2007). 
A teoria de sistemas, por sua vez, envolve aspectos relacionados à tomada de decisão, sistemas de comunicação, estrutura organizacional e questões de crescimento e incerteza (SILVA, 2002). Segundo o autor, a teoria promove o arcabouço necessário para desenvolver um ambiente propício e mais fácil para tomada de decisão.

Por sua vez "as organizações são um componente predominante na sociedade contemporânea" (HALL, 2004, p. 1), de tal forma que é praticamente impossível não manter algum tipo de relacionamento com as mesmas. Para Maximiano (2011, p. 4) "[...] um sistema de recursos que procura realizar algum tipo de objetivo (ou conjunto de objetivos)."

Vale ressaltar que os conceitos de organização e sistema legitimam-se uma vez que um sistema pode ser definido, como já mencionado, em "um conjunto de elementos dinamicamente relacionados, formando uma atividade para atingir um objetivo, operando sobre dados/energia/matéria para fornecer informação/energia/ matéria" (MUNIZ; FARIA, 2007, p. 221).

Não há dúvidas quanto à similaridade entre os conceitos de organização e de sistema de modo que a primeira é um subsistema (empresa), inserida em outro sistema (ambiente externo) com o qual interage. Conforme Silva (2002, p. 49), "qualquer que seja o tipo de classificação das organizações, a transformação ou conversão de entradas em saídas é um aspecto comum de todas as organizações". Entradas e saídas são aspectos característicos do conceito de sistema. Adicionalmente, de forma genérica, informação é um conjunto de dados relevantes. Oliveira (2009, p. 22), define informação como "[...] dado trabalhado que permite ao executivo tomar decisões".

O empresário rural deve observar que a decisão estratégica tem como foco a competitividade e para tanto depende fundamentalmente de informações referentes ao mercado, fornecedores, concorrentes, consumidores, inovações, ações da concorrência, entre outras. A informação é o elo que pode promover às empresas o equilíbrio entre as decisões assertivas e as incertezas do mundo globalizado. Deste modo a informação é essencial à competitividade.

O valor da informação é medido pela sua capacidade de ser determinante no processo de tomada de decisão. De acordo com Stair e Reynolds (2008, p. 4), 
a informação é um "[...] conjunto de fatos organizados de modo a terem valor adicional, além do valor dos fatos propriamente ditos". Os autores complementam o conceito ao considerarem que "a transformação de dados em informações é um processo ou conjunto de tarefas logicamente relacionadas desenvolvidas para atingir um resultado definido" (STAIR; REYNOLDS, 2008, p. 5).

$\mathrm{Na}$ opinião ainda de Stair e Reynolds (2008, p. 4), "um sistema de informação (SI) é um conjunto de componentes inter-relacionados que coletam, manipulam e disseminam dados e informações para proporcionar um mecanismo de realimentação para atingir um objetivo".

É primordial identificar com clareza as atividades de entrada, processamento, saída, armazenamento e controle característicos de todo sistema de informação (O’BRIEN, 2010). O sistema deve ser efetivo no sentido de resultar em produtos de informação que tenham valor para os usuários.

$\mathrm{Na}$ opinião de $\mathrm{O}^{\prime}$ Brien (2010), vale a pena vislumbrar a informação considerando a dimensão tempo, a dimensão conteúdo e a dimensão forma. Tais atributos estão expostos no Quadro 1.

Quadro 1. Resumo dos atributos da qualidade da informação. Define os atributos que devem estar presentes em produtos de informação de alta qualidade

(Continua)

\begin{tabular}{|l|l|}
\hline \multicolumn{2}{|l|}{ Dimensão tempo } \\
\hline Prontidão & A informação deve ser fornecida quando for necessária \\
\hline Aceitação & A informação deve estar atualizada quando for fornecida \\
\hline Frequência & A informação deve ser fornecida tantas vezes quantas forem necessárias \\
\hline Período & A informação pode ser fornecida sobre períodos passados, presentes e futuros \\
\hline Dimensão do conteúdo \\
\hline Precisão & A informação deve estar isenta de erros. \\
\hline Relevância & $\begin{array}{l}\text { A informação deve estar relacionada às necessidades de informação do receptor } \\
\text { para uma situação específica. }\end{array}$ \\
\hline Integridade & Toda informação que for necessária deve ser fornecida. \\
\hline Concisão & Apenas a informação que for necessária deve ser fornecida. \\
\hline Amplitude & A informação deve ter alcance amplo ou estreito, ou foco interno ou externo. \\
\hline Desempenho & $\begin{array}{l}\text { A informação pode revelar desempenho pela mensuração das atividades } \\
\text { concluídas, do progresso realizado ou dos recursos acumulados. }\end{array}$ \\
\hline
\end{tabular}


(Conclusão)

\begin{tabular}{|l|l|}
\hline \multicolumn{2}{|l|}{ Dimensão de forma } \\
\hline Clareza & A informação é fornecida de forma que seja fácil de compreender. \\
\hline Detalhe & A informação pode ser fornecida em forma detalhada ou resumida. \\
\hline Ordem & A informação pode ser organizada em sequência pré-determinada. \\
\hline Apresentação & $\begin{array}{l}\text { A informação pode ser apresentada em forma narrativa, numérica, gráfica ou } \\
\text { outras. }\end{array}$ \\
\hline Mídia & $\begin{array}{l}\text { A informação pode ser fornecida na forma de documentos, em papel impresso, } \\
\text { monitores de vídeos ou outras formas. }\end{array}$ \\
\hline
\end{tabular}

Fonte: O’Brien (2010, p. 15).

Considerando que a informação é um recurso primordial para a tomada de decisão e consequente desempenho da cadeia produtiva, os sistemas de informação tornam-se meios fundamentais para que a performance da mesma seja otimizada. Neste contexto, o entendimento do enfoque sistêmico é essencial.

As organizações rurais não podem mais ser analisadas de forma isolada uma vez que se encontram inseridas em um ambiente complexo com o qual mantêm interação e interdependência. Neste sentido, emerge o conceito de agronegócio visto como um sistema complexo (ZYLBERSZTAJN, 2000). Este autor (2000) traz a baila o conceito de agribusiness redefinido por Goldberg.

Um sistema de commodities engloba todos os atores envolvidos com a produção, processamento e distribuição de um produto. Tal sistema inclui o mercado de insumos agrícolas, produção agrícola, operações de estocagem, processamento, atacado e varejo, demarcando um fluxo que vai dos insumos até o consumidor final. O conceito engloba todas as instituições que afetam a coordenação dos estágios sucessivos do fluxo de produtos, tais como as instituições governamentais, mercados futuros e associações do comércio (GOLDBERG, 1968 apud ZILBERSZTAJN, 2000).

Para Castro (2001, p. 56) "os conceitos de agronegócio (ou negócio agrícola), de cadeia produtiva, sistema produtivo constituem aplicações da teoria geral dos sistemas, ou enfoque sistêmico".

O conceito de sistemas de um modo geral envolve componentes de entrada, transformação, saída e retroalimentação. Fundamentalmente o sistema não é uma soma de partes, mas um conjunto de partes que mantém interações e 
interdependências de tal modo que alterações em qualquer uma das partes pode afetar significativamente o todo. Isto é válido também para o agronegócio visto como sistema.

A definição de cadeia produtiva também está inserida na contextualização de visão sistêmica, uma vez que para atender o consumidor final com os bens produzidos, os diversos agentes pertencentes à cadeia produtiva se encontram interconectados por fluxos de materiais, de informação e de capital, portanto funcionando como um sistema (CASTRO; LIMA; CRISTO, 2002).

No que se refere aos Sistemas de Informação Gerenciais (SIG), de acordo com Oliveira (2009), o SIG envolve transformar dados em informações, sendo estas utilizadas como insumo para as decisões nas organizações de modo a proporcionar otimização dos resultados esperados. Para o autor, o SIG tem a função primordial de fornecer informações seguras ao tomador de decisão de modo que as decisões resultem na efetividade dos objetivos estabelecidos a priori.

A tomada de decisão só será assertiva quando baseada em informações condizentes com as alternativas de decisão e esta deve ter foco na competitividade. Destarte a informação tem valor quando seu resultado suscita maior capacidade competitiva para o sistema. De acordo com Williams (2010), a competitividade dos ambientes de negócios tornou a informação tão importante quanto o capital.

A proposta metodológica buscou a configuração do Sistema de informação do agronegócio da uva no Vale do São Francisco-PE pela perspectiva Insumo-Transformação-Produto. Tomando a tríade como um sistema aberto (de transformação), seu relacionamento com o meio dinâmico (os atores do agronegócio da uva) na perspectiva de entender como o sistema recebe os diversos insumos (dados e informações) os transforma e os exporta para os atores participantes. Isto se concebe pela compreensão de que a informação é um recurso crucial para o sucesso da cadeia produtiva da uva, enquanto sistema, no âmbito da região pesquisada.

Destarte, o presente estudo tem como foco final a compreensão do SIG do agronegócio da uva que envolve, especificamente, os produtores rurais do município de Petrolina e a Embrapa. Esses atores são elementos essenciais da cadeia produtiva da uva e esta se enquadra no contexto da visão ou enfoque sistêmico tratado no aporte teórico aqui descrito. 


\section{MATERIAL E MÉTODOS}

Os procedimentos escolhidos tiveram o intuito de responder aos seguintes questionamentos: como está estruturado o sistema de informação gerencial no âmbito do agronegócio da uva na região do São Francisco/PE, considerando os atores Embrapa, Produtores Rurais e mercado? E quais são os efeitos do SIG sobre a performance das unidades produtivas pesquisadas?

Não obstante saiba-se, conforme O'Brien (2010), que os sistemas de informação, a rigor, são baseados em conceitos básicos que incluem tendências, componentes e papéis do sistema; tecnologias da informação, evolvendo hardware, software, redes de telecomunicações e tecnologias de gerenciamento de banco de dados; aplicações comercias que incluem internet, intranets, extranets e outras tecnologias da informação para apoio aos negócios e tomadas de decisão; processos de desenvolvimento e implementação de sistemas e estratégias de negócios utilizando uma variedade de abordagens de desenvolvimento de aplicativos; e, por fim, desafios gerenciais incluindo a administração globalizada de TI e os desafios em termos de segurança e ética.

Como já mencionado, a proposta metodológica do presente estudo não buscou a configuração do sistema de informação do agronegócio da uva no Vale do São Francisco-PE pelos referenciais supramencionados, mas pela perspectiva Insumo-Transformação-Produto. Tomando a tríade como um sistema aberto (de transformação), seu relacionamento com o meio dinâmico (os atores do agronegócio da uva) na perspectiva de entender como o sistema recebe os diversos insumos (dados e informações) os transforma e os exporta para os atores participantes.

Considerou-se a informação como força impulsionadora dos negócios relacionados ao produto uva no Vale do São Francisco e, em consequência disso, destacou-se a informação como basal para os ganhos de produtividade no nível dos produtores de uva.

Para o cumprimento do objetivo delineado, levantaram-se informações junto a dois tipos de atores participantes do negócio uva: produtores rurais e Embrapa.

As informações foram obtidas no período de agosto de 2015 a dezembro do mesmo ano, dos dois atores mediante preenchimento de questionários. As questões tiveram como objetivo de atender as dimensões explanadas no Quadro 1. 
Foi fornecida pela instituição Valexport, instituição representante institucional do empresário hortigranjeiro da região do Vale do São Francisco/PE, uma lista composta por seus 38 associados. Destes 38 associados 21 produzem uvas e se encontram no município de Petrolina/PE e cidades circunvizinhas. Duas empresas são representadas pelo mesmo proprietário o que reduz a população para 20 respondentes.

Entre as 20 empresas que representam a população da região mencionada, seis empresas demonstraram grau de receptividade à pesquisa e responderam ao questionário. Vale ressaltar que entre os seis entrevistados se encontra uma cooperativa da região que representa 55 produtores, dos quais 54 são produtores de uvas.

Foi escolhida amostra sistemática da população estudada com base nos lotes de produção (com diferentes tamanhos) os quais representem dimensões fixas. Consequentemente, por este tipo de amostra, todos os tipos de lotes serão representados em proporções iguais ou bastante próximos, conforme demonstra Bueno (2010).

Para a Embrapa foi aplicado um questionário direcionado ao Setor de Prospecção e Avaliação de Tecnologias (SPAT).

Após tabulados os questionários e respostas das entrevistas, utilizou-se em princípio a estatística descritiva usando como referencial da apresentação dos dados os gráficos de frequência. Foram utilizados quadros para melhor explanar os resultados

No que se refere à construção dos questionários foram desenvolvidas questões baseadas no formato Likert, cujas opções de respostas contemplaram as seguintes escalas: discordo totalmente, discordo parcialmente, indeciso, concordo parcialmente e concordo totalmente.

Para analisar as respostas com escala Likert optou-se pela utilização do Ranking Médio (RM). O RM resultou da pontuação conferida a cada resposta e relacionada ao produto da frequência pelo número das respostas dos sujeitos (OLIVEIRA, 2005). 


\section{RESULTADO E DISCUSSÃO}

A primeira etapa da análise traz a baila os resultados da pesquisa com os produtores rurais da região de Petrolina e cidades circunvizinhas, em relação às informações provenientes da Embrapa e o fluxo de informação entre estes dois agentes, conforme Figura 1.

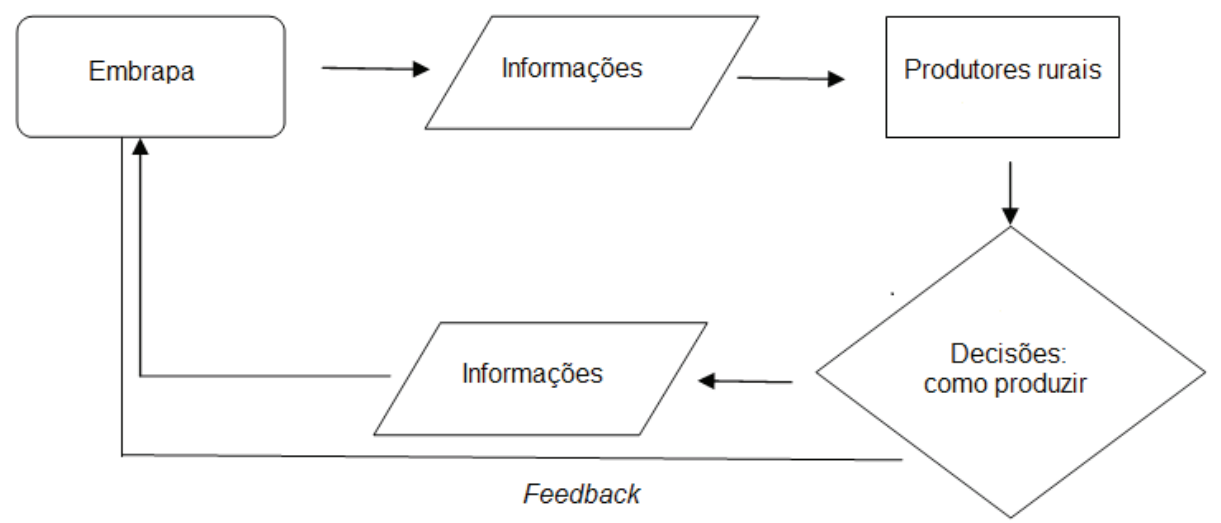

Figura 1. Sistema de informação composto pela Embrapa (Origem/fonte) e produtores rurais do Vale do São Francisco (Entrada). Fonte: Autora da pesquisa, 2016.

Com base na observação da Figura 1 tem-se a percepção de que, embora a instituição Embrapa e produtores rurais sejam agentes diferentes e independentes da cadeia produtiva da uva, subsiste uma interdependência entre as partes, vez que a Embrapa, conforme mencionado pelo respondente da pesquisa, busca fornecer informações aos produtores de uva do Vale do São Francisco oriundas dos resultados das pesquisas realizadas nas áreas de manejo cultural, fitossanitário, solos e água; Produção Integrada de Frutas $\left(\mathrm{PIF}^{8}\right)$ - Produção Integrada da Uva; melhoramento vegetal; biotecnologia; processamento de vinhos e sucos. Os produtores rurais, por sua vez, incluindo a Cooperativa, atuam utilizando informações da Embrapa em relação a conhecimentos e tecnologias utilizadas para melhoramento da produção de uva.

8 Disponível em: $<$ http://www.cpatsa.embrapa.br:8080/pif/uva/normas.htm > 
Nogueira (2007) afirma que a partir da teoria de sistemas foi possível entender as organizações como subsistemas capazes de gerar produtos ou serviços resultantes de processo e informação. Neste contexto, observa-se que estes agentes (produtores rurais e Embrapa) fazem parte de um sistema no qual a qualidade das saídas (considerando decisões a respeito de como produzir e que implicam diretamente na qualidade das uvas produzidas) depende também do fluxo de informações dos agentes mencionados e a efetividade de tal fluxo, uma vez que os produtores rurais respondentes utilizam informações da Embrapa.

No Gráfico 1 é identificado o atributo de qualidade do fluxo de informação no que se refere à dimensão tempo.

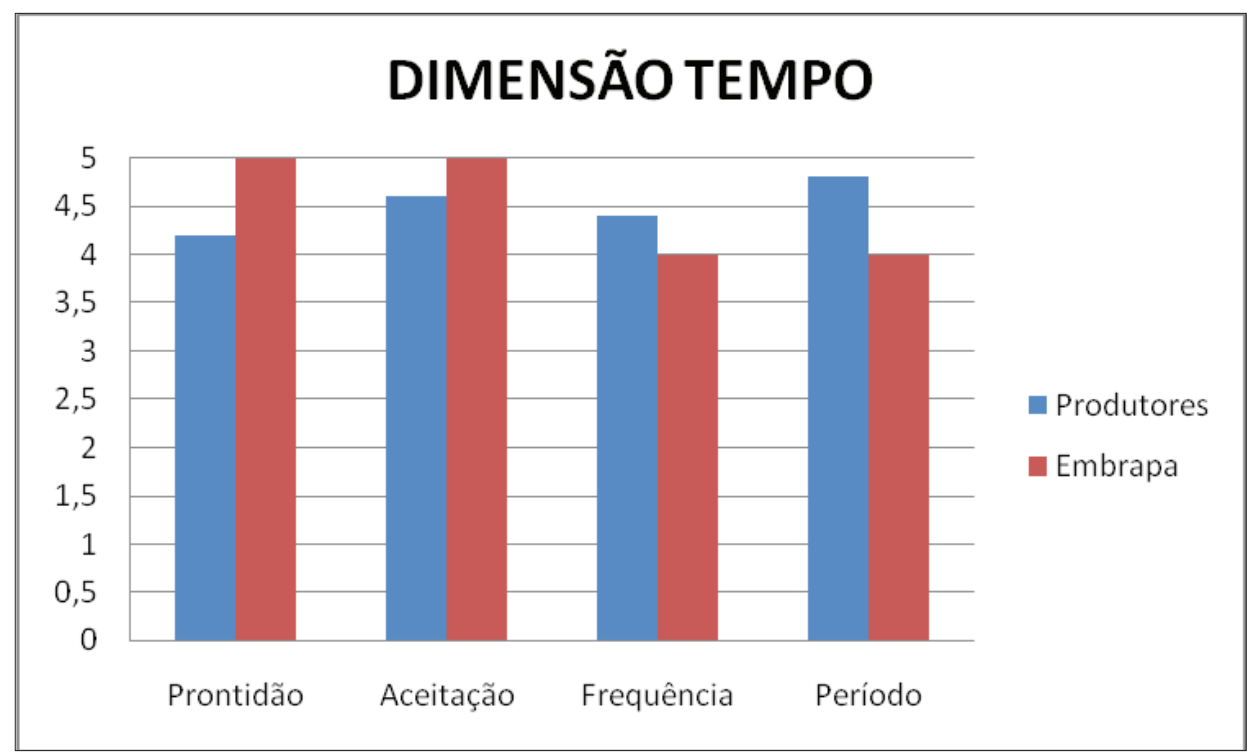

Gráfico 1. Atributos da qualidade da informação: dimensão tempo Fonte: Pesquisa de campo, 2015.

Observa-se que as respostas de produtores e da Instituição Embrapa consolidam-se no que se refere à dimensão tempo, uma vez que o ranking médio supera a escala 4. Ora, a assertividade da decisão em ambientes complexos requer dinamismo na entrada de recursos e neste contexto a dimensão tempo é essencial. Conforme mencionado por Stair e Reynolds (2008, p. 4), "um SI é um conjunto de componentes inter-relacionados que coletam, manipulam e disseminam dados 
e informações para proporcionar um mecanismo de realimentação para atingir um objetivo". Neste sentido, o sistema funcionará de forma coordenada quando a disseminação da informação ocorre em tempo hábil. Sendo primordial, ainda, a aceitação e uso de tal informação e isto parece ocorrer entre os agentes da cadeia produtiva da uva produtores rurais e Embrapa.

A dimensão conteúdo, conforme O’Brien (2010), considera os aspectos de precisão, relevância, integridade e desempenho. No Gráfico 2 é identificada a percepção dos produtores rurais a respeito do conteúdo fornecido pela Embrapa e a percepção que a instituição tem de si mesma em relação aos produtores sobre a mesma dimensão.

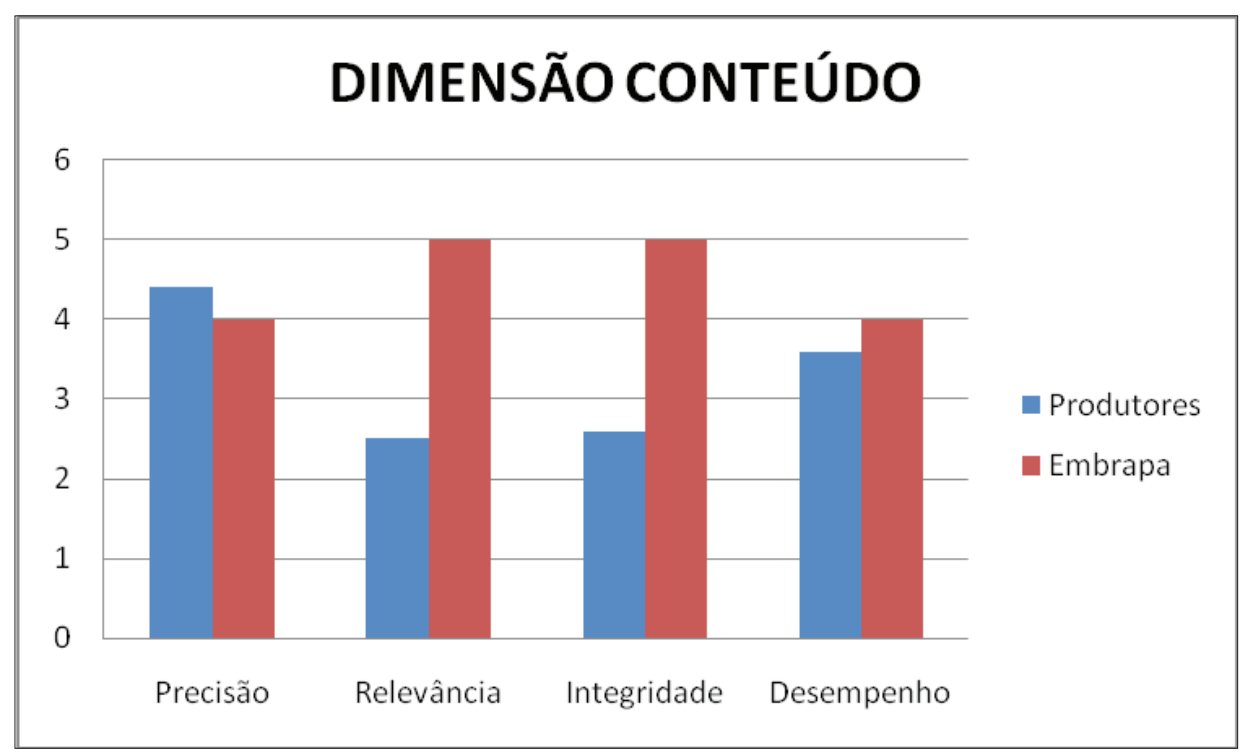

Gráfico 2. Atributos da qualidade da informação: dimensão conteúdo.

Fonte: Pesquisa de campo, 2015.

Tanto os produtores rurais quanto a Embrapa consideram que as informações oriundas desta instituição são praticamente isentas de erros, uma vez que o ranking médio das duas partes supera a escala 4. Todavia no quesito relevância da informação há uma lacuna entre os respondentes: para os produtores, a relevância encontra-se na escala de 2,5, para Embrapa a relevância é total, isto é escala 5. Os produtores entendem, ainda, que nem toda informação necessária está sendo fornecida (escala de 2,6), ou seja, a integridade está comprometida. 
A Embrapa por sua vez compreende que toda informação necessária está sendo fornecida (escala 5,0).

Embora para os produtores a relevância e integridade estejam comprometidas ainda assim as informações provenientes da Embrapa geram relativamente desempenho (escala 3,6), resposta corroborada pela Embrapa (escala $4,0)$.

Ora, só é possível gerar conhecimento por meio da informação e, consequentemente, decisões assertivas quando as informações são relevantes e íntegras. Para Stair e Reynolds (2008), o conhecimento é a compreensão de um conjunto de informações e maneiras de torná-las úteis à tomada de decisão. Para os autores o valor da informação está diretamente relacionado à capacidade de auxiliar na tomada de decisão.

A divergência de percepção entre Embrapa e produtores, principalmente relacionada à questão da relevância, pode limitar a capacidade da Embrapa em gerar, de fato, informações pertinentes, uma vez que para a mesma isto já acontece na prática.

No Gráfico 3 contém dados referentes à dimensão forma. Esta por sua vez contempla os atributos de qualidade da informação como a clareza, o detalhe, a ordem, a apresentação e a mídia.

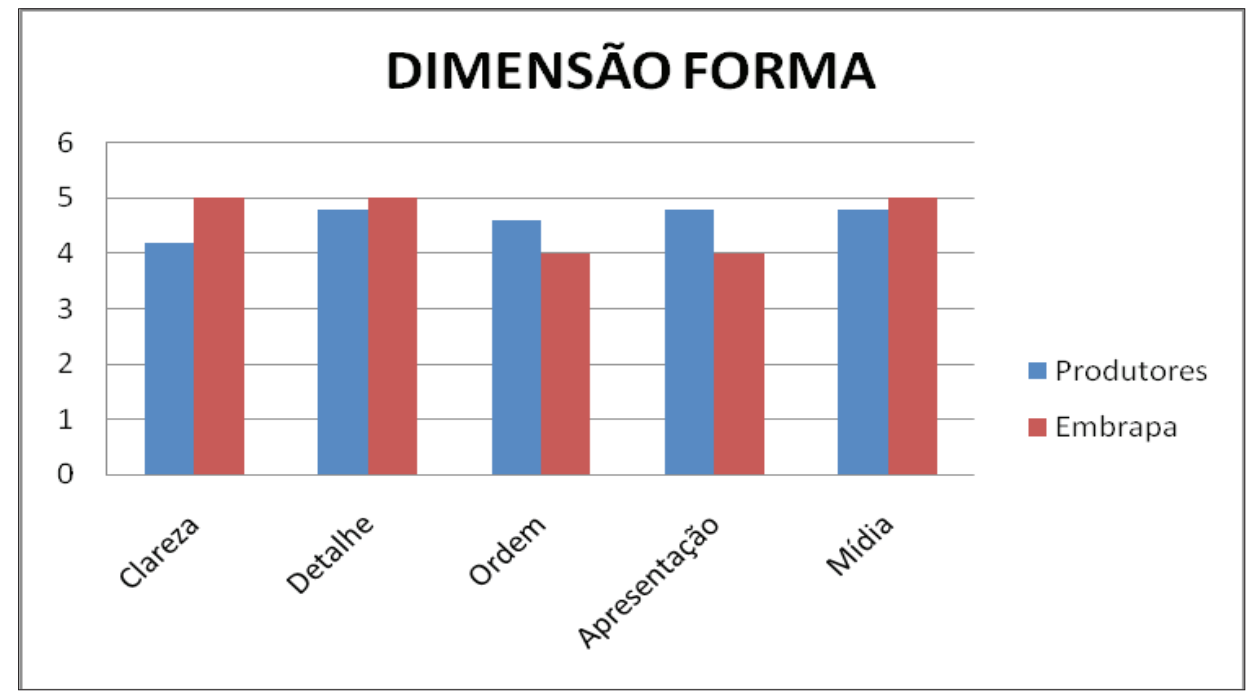

Gráfico 3. Atributos da qualidade da informação: dimensão conteúdo. Fonte: pesquisa de campo, 2015. 
Nestes quesitos os produtores rurais e a instituição Embrapa corroboram a respeito do resultado. Ambos os pesquisados entendem que as informações fornecidas pela instituição são claras, detalhadas, ordenadas, apresentadas em forma narrativa, numérica, gráfica ou outras. Além disso, as informações são apresentadas em mídias formais tais como documentos, papel impresso, monitores de vídeos ou outras formas.

O Gráfico 4, por sua vez, traz a baila os dados referentes ao nível de satisfação dos atores pesquisados no que tange as informações fornecidas pela Embrapa para os produtores rurais.

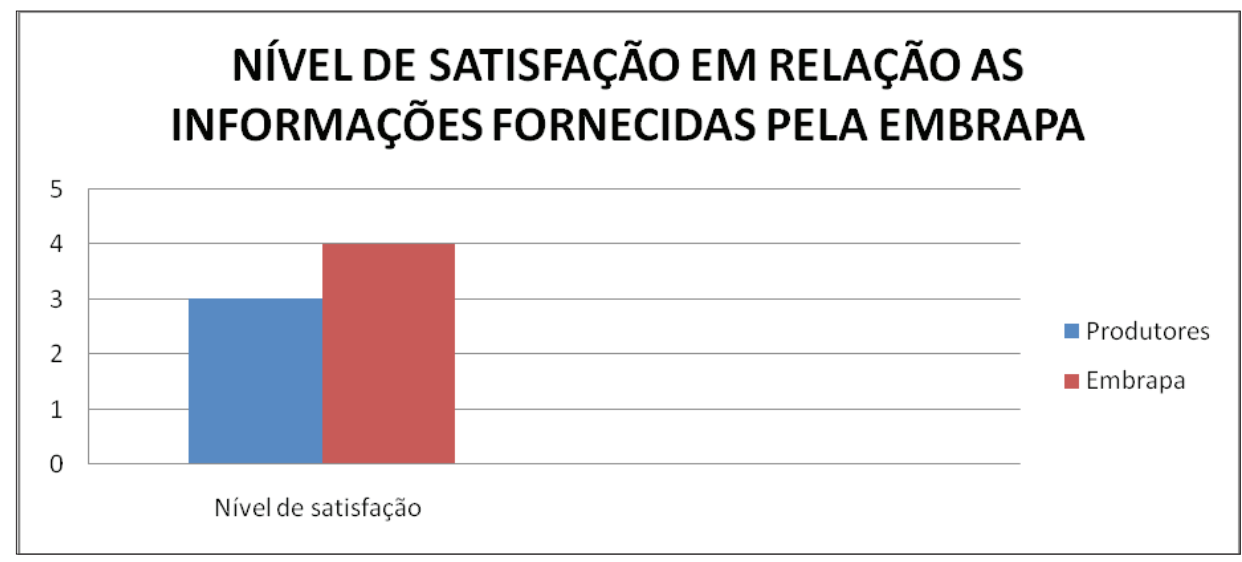

Gráfico 4. Nível de satisfação dos produtores rurais e da Embrapa no que se refere às informações fornecidas pela Embrapa aos produtores.

Fonte: Pesquisa de campo, 2015.

Comparado o nível de satisfação em relação às informações fornecidas pela Embrapa aos produtores rurais, estes se apresentam como indiferentes conforme resultado (escala 3), enquanto a instituição se apresenta satisfeita (escala 4). O representante da SPAT afirmou que após o fornecimento das informações aos produtores de uva, a Embrapa realiza feedback uma vez que há monitoramento através de visita às áreas produtivas (monitorando a adoção e desempenho das tecnologias, como exemplo nas áreas que adotaram a PIF); reuniões técnicas, seminários e workshops. No entanto, o nível de satisfação dos produtores demonstra que ainda há um gap entre as informações que a Embrapa oferece e as informações que os produtores rurais entendem que precisam. 
Por outro lado, vale ressaltar que entre as principais dificuldades encontradas pela Embrapa no que se refere à disseminação de informações aos produtores rurais está em reforçar o diálogo com os atores envolvidos na cadeia produtiva da uva na região do Vale São Francisco em particular com os produtores. Além da necessidade de aperfeiçoamento do processo de prospecção de demandas de ações de pesquisa com a cultura da uva junto aos atores da cadeia produtiva visando, cada vez mais, a elaboração de projetos que atendam às reais necessidades dos produtores/empresários. Então, mesmo estando satisfeita com as informações fornecidas a Embrapa demonstra compreender que é necessário acentuar o diálogo com os produtores e desenvolver projetos direcionados às necessidades fidedignas dos mesmos.

De um modo geral percebe-se que a Embrapa cumpre seu papel e sua missão ${ }^{9}$, uma vez que viabiliza soluções de pesquisa, desenvolvimento e inovação, auxiliando, deste modo os produtores no que se refere à produção de uvas com maior qualidade. Todavia, ainda é necessário compreender mais profundamente as reais necessidades dos produtores rurais com vista a atendê-las. Isto ocorrerá na medida em que o diálogo entre Embrapa e produtores tornar-se mais estreito e se compreende que isto será possível pelo desenvolvimento de formas de feedback por parte da Embrapa mais efetivo.

\section{CONSIDERAÇÕES FINAIS}

A análise empreendida no presente estudo suscitou conclusões aqui discutidas no que se refere à configuração do modelo de gestão da informação no âmbito no agronegócio da uva na região do São Francisco/PE.

A análise abrangeu o fluxo de informações entre os agentes da cadeia produtiva da uva, quais sejam: produtores rurais e Embrapa. A esse respeito compreendeu-se que embora sejam agentes independentes há uma relação de interdependência entre as partes, aspecto este típico de um sistema.

A interdependência mencionada se refere ao objetivo da Embrapa em oferecer conhecimentos resultantes de pesquisas no âmbito do agronegócio da uva

Disponível em: < https://www.embrapa.br/missao-visao-e-valores $>$ 
e, por outro lado, da necessidade dos produtores em utilizar os conhecimentos fornecidos pela instituição como informação ou recurso para tomada de decisão.

Concluiu-se que a Embrapa atua em parceria com os produtores rurais da região pesquisada promovendo impacto no desempenho de negócio destes últimos. Embora as duas partes concordem que ainda é necessário maior foco da instituição sobre as reais necessidades dos produtores, ficou claro que, indiscutivelmente, há um fluxo de informações efetivo quanto à saída de conhecimentos da instituição e entrada das informações como recursos para as empresas rurais. Observou-se que a qualidade das uvas também é resultado da parceria da Embrapa (fornecedora de conhecimentos) com os produtores rurais.

Como ponto crítico identificou-se que os atributos de qualidade relacionados à relevância e a integridade precisam de atenção por parte da instituição Embrapa. Ora, o valor da informação está intrinsecamente relacionado à relevância de tal informação. Neste critério houve uma lacuna entre a percepção da Embrapa e a dos produtores rurais. Destarte, compreendeu-se que a instituição precisa buscar meios efetivos de feedback com o intuito de compreender de modo claro as necessidades reais dos produtores, especialmente no que se refere às práticas do campo que resultem em produtos inovadores demandados pelo mercado. No entanto, é necessário ressaltar que a Embrapa não ignora tal necessidade. Um feedback efetivo tenderá a gerar maior integridade no contexto da dimensão conteúdo.

É imprescindível destacar que há interesse dos pesquisadores da Embrapa em atender as necessidades dos produtores rurais, todavia entendeu-se que o dinamismo do mercado e as demandas deste exigem pesquisas cada vez mais arrojadas. Por este motivo, alguns produtores, por iniciativa própria, desenvolvem estudos e pesquisas com o objetivo de gerar novos conhecimentos a serem aplicados ao negócio.

Por fim, concluiu-se que atualmente os produtores rurais pesquisados tratam a informação como insumo tão importante quanto qualquer outro recurso de entrada do sistema. E esta postura profissional característica do agronegócio gerou ações que, por sua vez, impactaram diretamente nos resultados alcançados no que se refere à dimensão do negócio, em nível de exportação e ao volume de uvas transacionadas no mercado. Neste contexto, a parceria com a Embrapa e o fluxo de 
informações entre estes atores da cadeia produtiva da uva impactaram positivamente no resultado final do agronegócio da uva na região pesquisada.

\section{REFERÊNCIAS}

ANGELONI, M.T. Elementos intervenientes na tomada de decisão. Ciência da Informação, Brasília, v. 32, n. 1, p. 17-22, jan./abr. 2003. Disponível em:<http:// www.scielo.br/pdf/ci/v32n1/15969.pdf>. Acesso em: 22 maio 2015.

A VITICULTURA NO SEMI-ÁRIDO BRASILEIRO. Petrolina: Embrapa Semi-Árido, 2000. ISBN 757405-003-2

BERTALLANFY, L. V. Teoria Geral dos Sistemas: fundamentos, desenvolvimento e aplicações. 6. ed. Petrópolis: Vozes, 2012.

BORGES, M. A. G. A. compreensão da sociedade da informação. Ciência da Informação, Brasília, v. 29, n. 3, 25-32, set./dez. 2000. Disponível em: < http:// revista.ibict.br/ciinf/index.php/ciinf/article/view/214>. Acesso em: 31 maio 2015.

BUENO, F. Estatística para processos produtivos. Florianópolis: Visual Books, 2010.

CASTRO, A. M. G. de. Prospecção de Cadeias Produtivas e Gestão da Informação. Transinformação, v. 13, n. 2, p. 55-72, jul./dez. 2001. Disponível em: < http://www. scielo.br/pdf/tinf/v13n2/04.pdf> . Acesso em: 28 mai. 2015.

CASTRO, A. M. G de; LIMA, S. M. V.; CRISTO, C. M. P. N. Cadeia produtiva: marco conceitual para apoiar a prospecção tecnológica. In: SIMPÓSIO DE GESTÃO E INOVAÇÃO TECNOLÓGICA, 22., 2002, Salvador. Anais eletrônicos... Salvador: ANPAD, 2002. 2-3 Disponível em: < http://www.camex.gov.br/portalmdic/arquivos/ dwnl_1197031881.pdf >. Acesso em: 28 jun. 2015.

EMBRAPA - EMPRESA BRASILEIRA DE PESQUISA AGROPECUÁRIA. A região do vale do rio São Francisco. Disponível em: < http://www.cnpma.embrapa.br/projetos/ prod_int/regiaosf.html>. Acesso em: 23 abr. 2015. 
HALL, R. H. Organizações: estruturas, processos e resultados. São Paulo: Pearson Prentice Hall, 2004.

IBGE - INSTITUTO BRASILEIRO DE GEOGRAFIA E ESTATÍSTICA. Disponível em: $<$ http://www.ibge.gov.br/home/estatistica/economia/pam/2013/default_perm_xls. shtm > . Acesso em: 28 maio 2015.

LAWRENCE, P. R.; LORSCH, J. W. O desenvolvimento de organizações: diagnóstico e ação. São Paulo: Edgard Blucher, reimpressão em 1977. Disponível em: < http:// www.cra-rj.org.br/site/leitura/textos_class/PAUL/publicacao/index.html\#/4/ zoomed > . Acesso em: 16 maio 2015.

MAXIMIANO, A. C. A. Introdução à Administração. 8. ed. rev. ampl. São Paulo: Atlas, 2011.

MAXIMIANO, A. C. A. Teoria geral da Administração: da revolução urbana à revolução digital. 6. ed. São Paulo: Atlas, 2007.

MUNIZ, A. J. O.; FARIA, H. A. Teoria Geral da Administração: noções básicas. 5. ed. rev. E ampl. São Paulo: Atlas, 2007.

NEVES, M.F. Sistema Agroindustrial Citrícola: um exemplo de quase-integração no agribusiness brasileiro. 1995. 88f. Dissertação de Mestrado. Faculdade de Economia, Administração e Contabilidade da Universidade de São Paulo, 1995. Disponível em: $<$ http://pensa.org.br/wp-content/uploads/2011/10/O_sistema_agroindustrial_ citricola_um_exemplo_de_quase-integracao_no_agribusiness_brasileiro_1995. pdf $>$. Acesso em: 28 jun. 2015.

NOGUEIRA, A. J. F. M. Teoria Geral da Administração para o século XXI. São Paulo: Ática, 2007.

NUNES, J. L. S. A agricultura de precisão como ferramenta para o produtor rural. Disponível em: <http://www.senar.org.br/agricultura-precisao/artigos-e-palestras/ artigo-a-agricultura-de-precisao-como-ferramenta-para-o-produtor-rural/ $>$. Acesso em: 20 out. 2015. 
O ’ BRIEN, J. A. Sistemas de informação gerenciais na era da Internet. 3. ed. São Paulo: Saraiva, 2010.

OLIVEIRA, D. P. R. Sistemas de Informações Gerenciais: estratégias, táticas operacionais. 13. ed. São Paulo: Atlas, 2009.

OLIVEIRA, L. H. de. Exemplo de cálculo de Ranking Médio para Likert. Notas de Aula. Metodologia Científica e Técnicas de Pesquisa em Administração. Mestrado em Adm. e Desenvolvimento Organizacional. PPGA CNEC/FACECA: Varginha, 2005. Disponível em: $<$ http://www.administradores.com.br/producao-academica/rankingmedio-para-escala-de-likert/28> Acesso em: 09 nov. 2015.

PRODUÇÃO AGRÍCOLA MUNICIPAL: CULTURAS TEMPORÁRIAS E PERMANENTES 2012. Rio de Janeiro: IBGE, 2012. Disponível em: $<$ http://biblioteca.ibge.gov.br/ visualizacao/periodicos/66/pam_2012_v39_br.pdf > . Acesso em: 26 maio 2015.

PRODUÇÃO AGRÍCOLA MUNICIPAL: CULTURAS TEMPORÁRIAS E PERMANENTES 2013. Rio de Janeiro: IBGE, 2013. Disponível em: $<$ http://biblioteca.ibge.gov.br/ visualizacao/periodicos/66/pam_2013_v40_br.pdf > . Acesso em: 26 maio 2015.

SILVA, R. O. da. Teoria da Administração. 1. ed. São Paulo: Pioneira Thomson Learning, 2002.

SILVA, P. C. G. da; COELHO. A. R. C. Cultivo da Videira: caracterização social e econômica da videira. Embrapa. 2010. Disponível em: < http://www.cpatsa. embrapa.br:8080/sistema_producao/spuva/Caracterizaca_social_da_\%20videira. html > . Acesso em: 26 maio 2015.

STAIR, R. M.; REYNOLDS, G. W. Princípios de sistemas de informação: uma abordagem gerencial. São Paulo: Cengage Learning, 2008.

WILLIANS, C. Administração. São Paulo: Cengage Learning, 2010.

ZYLBERSZTAJN, D. Conceitos gerais, evolução e apresentação do sistema agroindustrial. In: ZYLBERSZTAJN, D.; NEVES, M. F. (Org.). Economia e gestão dos 
negócios agroalimentares: indústria de alimentos, indústria de insumos, produção agropecuária, distribuição. São Paulo: Pioneira, 2000.

Recebido em: 22/02/2016 Aceito em: 31/03/2017 